Kragujevac Journal of Mathematics

Volume 39(1) (2015), Pages 13-20.

\title{
SOFT ROUGH LATTICE
}

\author{
SANKAR KUMAR ROY ${ }^{1}$ AND SUSANTA BERA ${ }^{2}$
}

\begin{abstract}
Rough and soft sets are both mathematical tools for dealing with uncertainty. But soft set theory is utilized for the first time, to generalize Pawlak's rough set model. Soft rough set is a connection between these two mathematical approaches to vagueness. In this study, we find a algebraic connection between soft rough set and algebraic system and thereby introduce the notion of soft rough lattice in a soft approximation space. We define the concept of a soft rough lattice, soft rough sublattice, modular soft rough lattice and distributive soft rough lattice. Finally, we cite some examples to illustrate the definitions.
\end{abstract}

\section{INTRODUCTION}

In 1999, Molodtsov [1] introduced soft set as a mathematical tool for dealing with uncertainty. Thereafter a rapid growth of applications $[1,2]$ of soft set has been found in many fields of mathematics. Maji et al. [3] discussed the application of soft set theory in a decission making problem. Yang et al. [4] introduced interval-valued fuzzy soft sets. Maji et al. [5] defined the operations of soft set and a theoretical study on soft set. Aktas and Cağman [6] found a algebraic connection between soft set and algebraic system and introduced soft groups. The lattice structure of soft set has been found in $[7,8]$

Rough set theory was introduced by Pawlak [9] is a another mathematical approach to vagueness. This theory deals with two key notions: rough set approximations and information systems. Rough set approximations are defined by means of an equivalence relation namely indiscernibility relation. Every rough sets are associated with two crisp sets, called lower and upper approximations and viewed as the sets of elements which certainly and possibly belong to the set. It has been successfully applied to knowledge discovery, decision analysis, signal processing, mereology and

Key words and phrases. Soft set, rough set, soft approximation space, soft rough set, lattice.

2010 Mathematics Subject Classification. Primary: 03G10. Secondary: 06D10, 06D15.

Received: October 7, 2013

Accepted: February 18, 2015. 
many other fields. Iwinski [10] defined rough lattice and order without using any concept of indiscernibility of rough set. Rana and Roy [11] introduced rough set approach on lattice.

The rough set theory is often a useful and powerful approach to dealing with uncertainty but have some inherent difficulties mentioned by Molodtsov [1]. Soft set theory is a possible way to solve the difficulties of rough set. Thereafter a possible fusion of rough set and soft set has been proposed by Feng et al. [12] for the first time and introduced the concept of soft rough set. In this theory generalized rough set has been studied based on soft set.

In this study, we find a algebraic connection between soft rough set and algebraic system and thereby introduced the notion of soft rough lattice in a soft approximation space. To proceed this work we introduced some operation on soft rough set like soft rough union soft rough intersection, soft rough inclusion in section 2. We also present soft rough sublattice, soft rough modular lattice and soft rough distributive lattice and discussed their related properties.

\section{Soft Set and Soft Rough Set: An Overview}

Here we recall some basic properties and definitions related to soft set and soft rough set.

Let $U$ be an initial universe of objects and $E$ be the set of parameters and $A \subseteq E$. $P(U)$ is the power set of $U$.

Definition 2.1. [1] A pair $S=(F, A)$ is called a soft set over $U$, where $F: A \rightarrow P(U)$ is a set valued mapping.

Definition 2.2. [12] Let $S=(F, A)$ be a soft set over $U$. Then the pair $P=(U, S)$ is called a soft approximation space. Let $X \subseteq U$. We defined the following operations on $P$

$$
\begin{aligned}
& \underline{\operatorname{apr}}(X)=\bigcup_{a \in A}\{F(a): F(a) \subseteq X\}, \\
& \overline{\operatorname{apr}}(X)=\bigcup_{a \in A}\{F(a): F(a) \cap X \neq \phi\},
\end{aligned}
$$

which are called soft lower and upper approximations respectively of $X$ and the pair $(\operatorname{apr}(X), \overline{\operatorname{apr}}(X))$ is called soft rough set of $X$ with respect to $P$ and is denoted by $\overline{S_{r}(X)}$. If $\operatorname{apr}(X)=\overline{\operatorname{apr}}(X), X$ is said to be soft definable; otherwise $X$ is called soft rough set. The set of all soft rough sets over $U$ is denoted by $S_{R}(U)$ with respect to some soft approximation space $P$.

Suppose $S=(F, A)$ is a soft set over $U$ and $P=(U, S)$ is the corresponding soft approximation space. Then soft approximations satisfy the following properties:

(i) $\operatorname{apr}(\phi)=\overline{\operatorname{apr}}(\phi)=\phi$,

(ii) $\underline{\operatorname{apr}}(U)=\overline{\operatorname{apr}}(U)=\bigcup_{a \in A}\{F(a)\}$, 
(iii) $\operatorname{apr}(X \cap Y) \subseteq \operatorname{apr}(X) \cap \operatorname{apr}(Y)$,

(iv) $\overline{\operatorname{apr}}(X \cup Y) \supseteq \overline{\operatorname{apr}}(X) \cup \overline{\operatorname{apr}}(Y)$,

(v) $\overline{\overline{\operatorname{apr}}}(X \cup Y)=\overline{\overline{\operatorname{apr}}}(X) \cup \overline{\overline{\operatorname{apr}}}(Y)$,

(vi) $\overline{\operatorname{apr}}(X \cap Y) \subseteq \overline{\operatorname{apr}}(X) \cap \overline{\operatorname{apr}}(Y)$,

(vii) $X \subseteq Y \Rightarrow \operatorname{apr}(X) \subseteq \operatorname{apr}(Y)$ and $\overline{\operatorname{apr}}(X) \subseteq \overline{\operatorname{apr}}(Y)$.

Definition 2.3. Let $S_{r}(X)=(\underline{\operatorname{apr}}(X), \overline{\operatorname{apr}}(X))$ and $S_{r}(Y)=(\operatorname{apr}(Y), \overline{\operatorname{apr}}(Y))$ be two soft rough set. Then soft rough union and soft rough intersection of $S_{r}(X)$ and $S_{r}(Y)$ are defined by $S_{r}(X) \sqcup S_{r}(Y)=(\operatorname{apr}(X) \cup \operatorname{apr}(Y), \overline{\operatorname{apr}}(X) \cup \overline{\operatorname{apr}}(Y))$ and $S_{r}(X) \sqcap S_{r}(Y)=(\operatorname{apr}(X) \bigcap \operatorname{apr}(Y), \overline{\operatorname{apr}}(X) \bigcap \overline{\overline{\operatorname{apr}}}(Y)) \overline{\text { respectively, where the symbols }}$ $\sqcup$ and $\sqcap$ stand for soft rough union and intersection respectively.

Definition 2.4. Let $S_{r}(X)=(\operatorname{apr}(X), \overline{\operatorname{apr}}(X))$ and $S_{r}(Y)=(\operatorname{apr}(Y), \overline{\operatorname{apr}}(Y))$ be two soft rough set. Then $S_{r}(Y)$ is said to be soft rough subset of $\overline{S_{r}}(X)$, denoted by $S_{r}(Y) \sqsubseteq S_{r}(X)$ if $\operatorname{apr}(Y) \subseteq \underline{\operatorname{apr}}(X)$ and $\overline{\operatorname{apr}}(Y) \subseteq \overline{\operatorname{apr}}(X)$, where $\sqsubseteq$ stands for soft rough inclusion relation.

\section{Soft Rough Lattice}

Let $S=(F, A)$ be a soft set over $U$ and $P=(U, S)$ be a soft approximation space and $S_{R}(U)$ be the set of all soft rough sets with respect to $P$.

Definition 3.1. Let $L \subseteq S_{R}(U)$, and $\vee$ and $\wedge$ be two binary operations on $L$. The algebraic structure $(L, \vee, \wedge)$ is said to be soft rough lattice if

(i) $\vee$ and $\wedge$ are associative,

(ii) $\vee$ and $\wedge$ are commutative,

(iii) $\vee$ and $\wedge$ satisfied absorption laws.

\begin{tabular}{c|cccccc}
$\sqcup$ & $S_{r}\left(X_{1}\right)$ & $S_{r}\left(X_{2}\right)$ & $S_{r}\left(X_{3}\right)$ & $S_{r}\left(X_{4}\right)$ & $S_{r}\left(X_{5}\right)$ & $S_{r}\left(X_{6}\right)$ \\
\hline$S_{r}\left(X_{1}\right)$ & $S_{r}\left(X_{1}\right)$ & $S_{r}\left(X_{2}\right)$ & $S_{r}\left(X_{3}\right)$ & $S_{r}\left(X_{4}\right)$ & $S_{r}\left(X_{5}\right)$ & $S_{r}\left(X_{6}\right)$ \\
$S_{r}\left(X_{2}\right)$ & $S_{r}\left(X_{2}\right)$ & $S_{r}\left(X_{2}\right)$ & $S_{r}\left(X_{2}\right)$ & $S_{r}\left(X_{5}\right)$ & $S_{r}\left(X_{5}\right)$ & $S_{r}\left(X_{6}\right)$ \\
$S_{r}\left(X_{3}\right)$ & $S_{r}\left(X_{3}\right)$ & $S_{r}\left(X_{2}\right)$ & $S_{r}\left(X_{3}\right)$ & $S_{r}\left(X_{4}\right)$ & $S_{r}\left(X_{5}\right)$ & $S_{r}\left(X_{6}\right)$ \\
$S_{r}\left(X_{4}\right)$ & $S_{r}\left(X_{4}\right)$ & $S_{r}\left(X_{5}\right)$ & $S_{r}\left(X_{4}\right)$ & $S_{r}\left(X_{4}\right)$ & $S_{r}\left(X_{5}\right)$ & $S_{r}\left(X_{6}\right)$ \\
$S_{r}\left(X_{5}\right)$ & $S_{r}\left(X_{5}\right)$ & $S_{r}(U)$ & $S_{r}(U)$ & $S_{r}(U)$ & $S_{r}(U)$ & $S_{r}(U)$ \\
$S_{r}\left(X_{6}\right)$ & $S_{r}(U)$ & $S_{r}(U)$ & $S_{r}(U)$ & $S_{r}(U)$ & $S_{r}(U)$ & $S_{r}(U)$
\end{tabular}

TABLE 1. Soft Rough Union on $L$

Example 3.1. Let $U=\left\{u_{1}, u_{2}, u_{3}\right\}, A=\left\{e_{1}, e_{2}, e_{3}, e_{4}\right\}$. Let $S=(F, A)$ be a soft set over $U$ given by $F\left(e_{1}\right)=\left\{u_{1}\right\}, F\left(e_{2}\right)=\left\{u_{3}\right\}, F\left(e_{3}\right)=\phi, F\left(e_{4}\right)=\left\{u_{1}, u_{3}\right\}$. Let $X_{1}=\phi, X_{2}=\left\{u_{1}\right\}, X_{3}=\left\{u_{2}\right\}, X_{4}=\left\{u_{2}, u_{3}\right\}, X_{5}=\left\{u_{1}, u_{3}\right\}$. For simplicity, we denote the subset of $U$, other than $\phi$ and $U$ by sequence of letters. For example $\left\{u_{1}, u_{3}\right\}$ is written as $u_{1} u_{3}$. The soft rough sets on the soft approximation 
space $P=(U, S)$ are given by $S_{r}\left(X_{1}\right)=(\phi, \phi), S_{r}\left(X_{2}\right)=\left(u_{1}, u_{1} u_{2}\right), S_{r}\left(X_{3}\right)=$ $\left(\phi, u_{1} u_{2}\right), S_{r}\left(X_{4}\right)=\left(u_{3}, U\right), S_{r}\left(X_{5}\right)=\left(u_{1} u_{3}, U\right), S_{r}(U)=(U, U)$. Then the set $L=\left\{S_{r}\left(X_{1}\right), S_{r}\left(X_{2}\right), S_{r}\left(X_{3}\right), S_{r}\left(X_{4}\right), S_{r}\left(X_{5}\right), S_{r}(U)\right\}$ form soft rough lattice with the operations $\sqcup$ and $\sqcap$ which are shown in the Tables 1 and 2 .

\begin{tabular}{c|cccccc}
$\sqcap$ & $S_{r}\left(X_{1}\right)$ & $S_{r}\left(X_{2}\right)$ & $S_{r}\left(X_{3}\right)$ & $S_{r}\left(X_{4}\right)$ & $S_{r}\left(X_{5}\right)$ & $S_{r}\left(X_{6}\right)$ \\
\hline$S_{r}\left(X_{1}\right)$ & $S_{r}\left(X_{1}\right)$ & $S_{r}\left(X_{1}\right)$ & $S_{r}\left(X_{1}\right)$ & $S_{r}\left(X_{1}\right)$ & $S_{r}\left(X_{1}\right)$ & $S_{r}\left(X_{1}\right)$ \\
$S_{r}\left(X_{2}\right)$ & $S_{r}\left(X_{1}\right)$ & $S_{r}\left(X_{2}\right)$ & $S_{r}\left(X_{3}\right)$ & $S_{r}\left(X_{3}\right)$ & $S_{r}\left(X_{2}\right)$ & $S_{r}\left(X_{2}\right)$ \\
$S_{r}\left(X_{3}\right)$ & $S_{r}\left(X_{1}\right)$ & $S_{r}\left(X_{3}\right)$ & $S_{r}\left(X_{3}\right)$ & $S_{r}\left(X_{3}\right)$ & $S_{r}\left(X_{3}\right)$ & $S_{r}\left(X_{3}\right)$ \\
$S_{r}\left(X_{4}\right)$ & $S_{r}\left(X_{1}\right)$ & $S_{r}\left(X_{3}\right)$ & $S_{r}\left(X_{3}\right)$ & $S_{r}\left(X_{4}\right)$ & $S_{r}\left(X_{4}\right)$ & $S_{r}\left(X_{4}\right)$ \\
$S_{r}\left(X_{5}\right)$ & $S_{r}\left(X_{1}\right)$ & $S_{r}\left(X_{2}\right)$ & $S_{r}\left(X_{3}\right)$ & $S_{r}\left(X_{4}\right)$ & $S_{r}\left(X_{5}\right)$ & $S_{r}\left(X_{5}\right)$ \\
$S_{r}\left(X_{6}\right)$ & $S_{r}\left(X_{1}\right)$ & $S_{r}\left(X_{2}\right)$ & $S_{r}\left(X_{3}\right)$ & $S_{r}\left(X_{4}\right)$ & $S_{r}\left(X_{5}\right)$ & $S_{r}\left(X_{6}\right)$
\end{tabular}

TABLE 2. Soft Rough Intersection on $L$

The Hasse diagram of this soft rough lattice appear in Figure 1.

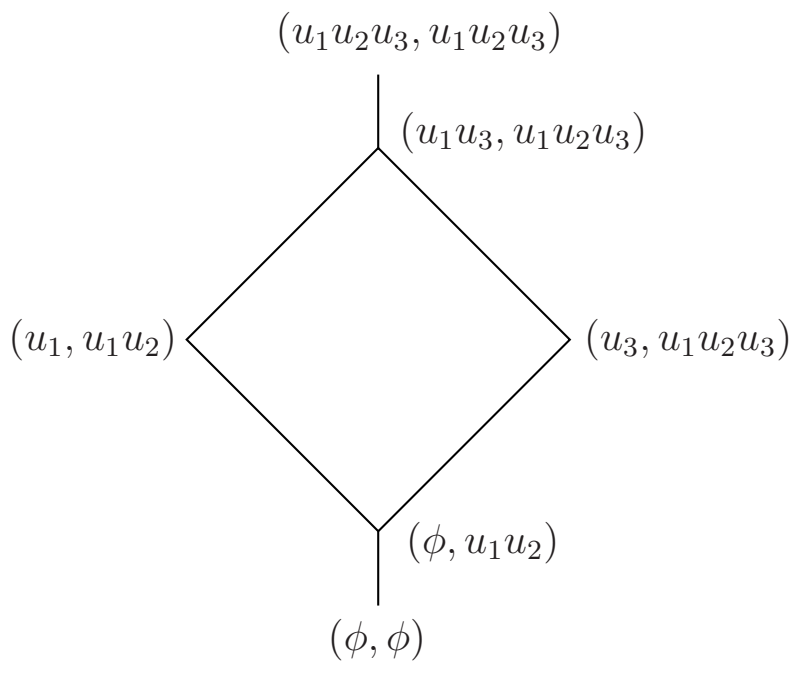

FiguRE 1. Soft rough lattice

Theorem 3.1. Let $(L, \vee, \wedge)$ be a soft rough lattice and $S_{r}(X), S_{r}(Y) \in L$. Then a relation $\preceq$ defined by $S_{r}(X) \preceq S_{r}(Y) \Leftrightarrow S_{r}(X) \vee S_{r}(Y)=S_{r}(Y)$ or $S_{r}(X) \wedge S_{r}(Y)=$ $S_{r}(X)$ is an order relation on $L$.

Proof. Reflexive: $S_{r}(X) \preceq S_{r}(X) \Leftrightarrow S_{r}(X) \vee S_{r}(X)=S_{r}(X)$.

Antisymmetric: Let $S_{r}(X) \preceq S_{r}(Y)$ and $S_{r}(Y) \preceq S_{r}(X)$. Then $S_{r}(X)=S_{r}(X) \wedge$ $S_{r}(Y)=S_{r}(Y) \wedge S_{r}(X)=S_{r}(Y)$ 
Transitive: Let $S_{r}(X) \preceq S_{r}(Y)$ and $S_{r}(Y) \preceq S_{r}(Z)$. Then $S_{r}(X) \wedge S_{r}(Z)=$ $\left(S_{r}(X) \wedge S_{r}(Y)\right) \wedge S_{r}(Z)=S_{r}(X) \wedge\left(S_{r}(Y) \wedge S_{r}(Z)\right)=S_{r}(X) \wedge S_{r}(Y)=S_{r}(X)$.

Therefore $S_{r}(X) \preceq S_{r}(Z)$.

Lemma 3.1. Let $L \in S_{R}(U)$. The soft rough inclusion relation ' $\sqsubseteq$ ' is an order relation on $L$.

Theorem 3.2. Let $(L, \vee, \wedge)$ be a soft rough lattice and $S_{r}(X), S_{r}(Y) \in L$. Then

(i) $S_{r}(X) \wedge S_{r}(Y) \preceq S_{r}(X)$ and $S_{r}(X) \wedge S_{r}(Y) \preceq S_{r}(Y)$

(ii) $S_{r}(X) \preceq S_{r}(Y) \vee S_{r}(X)$ and $S_{r}(Y) \preceq S_{r}(X) \vee S_{r}(Y)$.

Proof. (i) By the definition of order relation ' $\preceq$ ',

$$
\left(S_{r}(X) \wedge S_{r}(Y)\right) \vee S_{r}(X)=S_{r}(X) \vee\left(S_{r}(X) \wedge S_{r}(Y)\right)=S_{r}(X)
$$

Therefore $S_{r}(X) \vee S_{r}(Y) \preceq S_{r}(X)$.

Similarly proof of (ii) can be made.

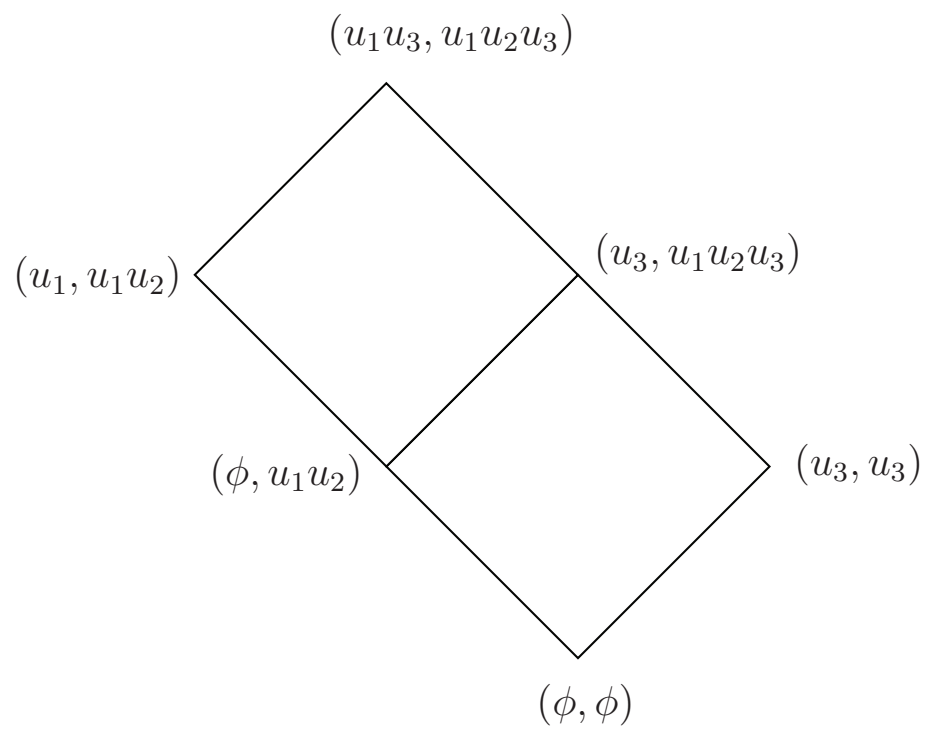

FIGURE 2. Distributive soft rough lattice

Theorem 3.3. Let $(L, \vee, \wedge)$ be a soft rough lattice and $S_{r}(W), S_{r}(X), S_{r}(Y), S_{r}(Z) \in$ $L$. Then from $S_{r}(W) \preceq S_{r}(X)$ and $S_{r}(Y) \preceq S_{r}(Z)$ it follows that

(i) $S_{r}(W) \wedge S_{r}(Y) \preceq S_{r}(X) \wedge S_{r}(Z)$ and

(ii) $S_{r}(W) \vee S_{r}(Y) \preceq S_{r}(X) \vee S_{r}(Z)$.

Proof. From the Theorem 3.1, we have

$$
S_{r}(W) \wedge S_{r}(X)=S_{r}(W) \text { and } S_{r}(Y) \wedge S_{r}(Z)=S_{r}(Y) .
$$


Now

$$
\begin{aligned}
{\left[S_{r}(W) \wedge S_{r}(Y)\right] \wedge\left[S_{r}(X) \wedge S_{r}(Z)\right] } & =\left[S_{r}(W) \wedge S_{r}(X) \wedge S_{r}(Y)\right] \wedge S_{r}(Z) \\
& =\left[\left(S_{r}(W) \wedge S_{r}(X)\right) \wedge S_{r}(Y)\right] \wedge S_{r}(Z) \\
& =\left[S_{r}(W) \wedge S_{r}(Y)\right] \wedge S_{r}(Z) \\
& =S_{r}(W) \wedge\left[S_{r}(Y) \wedge S_{r}(Z)\right] \\
& =S_{r}(W) \wedge S_{r}(Y) .
\end{aligned}
$$

Hence proved.

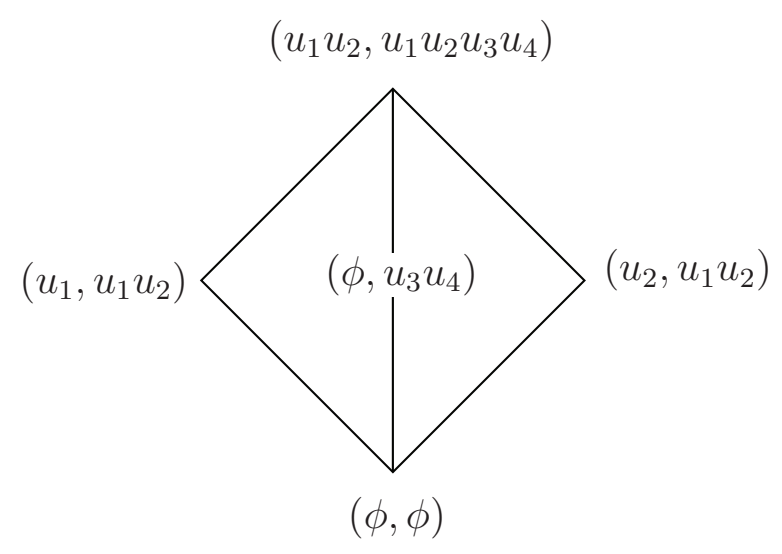

Figure 3. Modular soft rough lattice

Theorem 3.4. $S_{r}(X) \vee S_{r}(Y)$ and $S_{r}(X) \wedge S_{r}(Y)$ are the least upper and greatest lower bounds of $S_{r}(X)$ and $S_{r}(Y)$ respectively.

Proof. From the Theorem $3.2 S_{r}(X) \wedge S_{r}(Y)$ and $S_{r}(X) \vee S_{r}(Y)$ are lower and upper bounds of $S_{r}(X)$ and $S_{r}(Y)$ respectively. Now we are to show that these lower and upper bounds are respectively greatest lower bound and least upper bound of $S_{r}(X)$ and $S_{r}(Y)$. Assume that, $S_{r}(X) \wedge S_{r}(Y)$ is not greatest lower bound of $S_{r}(X)$ and $S_{r}(Y)$. Then there exist $S_{r}(Z)$ such that $S_{r}(X) \wedge S_{r}(Y) \preceq S_{r}(Z) \preceq S_{r}(X)$ and $S_{r}(X) \wedge S_{r}(Y) \preceq S_{r}(Z) \preceq S_{r}(Y)$. Hence $S_{r}(Z) \wedge S_{r}(Z) \preceq S_{r}(X) \wedge \bar{S}_{r}(Y)$ or $S_{r}(Z) \preceq S_{r}(X) \wedge S_{r}(Y)$. Therefore $S_{r}(Z)=S_{r}(X) \wedge S_{r}(Y)$. Hence a contradiction arises. Therefore $S_{r}(X) \wedge S_{r}(Y)$ is the greatest lower bound of $S_{r}(X)$ and $S_{r}(Y)$.

By the similar way we can show that $S_{r}(X) \vee S_{r}(Y)$ is the least upper bound of $S_{r}(X)$ and $S_{r}(Y)$.

Definition 3.2. Let $(L, \vee, \wedge, \preceq)$ be a soft rough lattice and $K \subseteq L$. If $K$ is a soft rough lattice with the operation of $L$ then $K$ is called soft rough sublattice of $L$.

Example 3.2. In Example 3.1, let $K=\left\{S_{r}\left(X_{2}\right), S_{r}\left(X_{3}\right), S_{r}\left(X_{4}\right), S_{r}\left(X_{5}\right)\right\}$. Then $K$ is a soft rough sublattice of $L$.

Theorem 3.5. Every soft rough lattice is a soft rough sublattice itself. 
Definition 3.3. A soft rough lattice $(L, \vee, \wedge, \preceq)$ is said to be distributive soft rough lattice if for every $S_{r}(X), S_{r}(Y), S_{r}(Z) \in L$, then

$$
S_{r}(X) \wedge\left(S_{r}(Y) \vee S_{r}(Z)\right)=\left(S_{r}(X) \wedge S_{r}(Y)\right) \vee\left(S_{r}(X) \wedge S_{r}(Z)\right)
$$

Example 3.3. For the soft set $(F, A)$ given in Example 3.1 if we consider $X_{1}=\phi, X_{2}=$ $\left\{u_{2}\right\}, X_{3}=\left\{u_{3}\right\}, X_{4}=\left\{u_{1}, u_{2}\right\}, X_{5}=\left\{u_{2}, u_{3}\right\}, X_{6}=\left\{u_{1}, u_{3}\right\}$, then $S_{r}\left(X_{1}\right)=(\phi, \phi)$, $S_{r}\left(X_{2}\right)=\left(\phi, u_{1} u_{2}\right), S_{r}\left(X_{3}\right)=\left(u_{3}, u_{3}\right), S_{r}\left(X_{4}\right)=\left(u_{1}, u_{1} u_{2}\right), S_{r}\left(X_{5}\right)=\left(u_{3}, u_{1} u_{2} u_{3}\right)$, $S_{r}\left(X_{6}\right)=\left(u_{1} u_{3}, u_{1} u_{2} u_{3}\right)$. Then the set

$$
L=\left\{S_{r}\left(X_{1}\right), S_{r}\left(X_{2}\right), S_{r}\left(X_{3}\right), S_{r}\left(X_{4}\right), S_{r}\left(X_{5}\right), S_{r}\left(X_{6}\right)\right\}
$$

is distributive soft rough lattice with the operation $\sqcup, \sqcap$. The Hasse diagram of it appears in Figure 2.

Definition 3.4. A soft rough lattice $(L, \vee, \wedge, \preceq)$ is said to be modular soft rough lattice if for every $S_{r}(X), S_{r}(Y), S_{r}(Z) \in L$, with $S_{r}(X) \succeq S_{r}(Y)$ the following equality holds

$$
S_{r}(X) \wedge\left(S_{r}(Y) \vee S_{r}(Z)\right)=S_{r}(Y) \vee\left(S_{r}(X) \wedge S_{r}(Z)\right) .
$$

Example 3.4. Let $U$ be the set of universe and $A$ be the set of parameters are defined as: $U=\left\{u_{1}, u_{2}, u_{3}, u_{4}\right\}$ and $A=\left\{e_{1}, e_{2}, e_{3}, e_{4}\right\}$. Let the soft set $S=(U, A)$ over $U$ is given by $F\left(e_{1}\right)=\left\{u_{1}, u_{2}\right\}, F\left(e_{2}\right)=\left\{u_{1}\right\}, F\left(e_{3}\right)=\left\{u_{3}, u_{4}\right\}, F\left(e_{4}\right)=\left\{u_{2}\right\}$. Let $X_{1}=\phi, X_{2}=\left\{u_{1}\right\}, X_{3}=\left\{u_{4}\right\}, X_{4}=\left\{u_{2}\right\}, X_{5}=\left\{u_{1}, u_{2}, u_{3}\right\}$. Then the soft rough sets on the soft approximation space $P=(U, S)$ are given by $S_{r}\left(X_{1}\right)=(\phi, \phi)$, $S_{r}\left(X_{2}\right)=\left(u_{1}\right), S_{r}\left(X_{3}\right)=\left(\phi, u_{3} u_{4}\right), S_{r}\left(X_{4}\right)=\left(u_{2}, u_{1} u_{2}\right), S_{r}\left(X_{5}\right)=\left(u_{1} u_{2}, u_{1} u_{2} u_{3} u_{4}\right)$. Then the set $L=\left\{S_{r}\left(X_{1}\right), S_{r}\left(X_{2}\right), S_{r}\left(X_{3}\right), S_{r}\left(X_{4}\right), S_{r}\left(X_{5}\right)\right\}$ is modular soft rough lattice. Hasse diagram of it appears in Figure 3

Theorem 3.6. A distributive soft rough lattice is always modular soft rough lattice.

Proof. Let $(L, \vee, \wedge, \preceq)$ is said to be distributive soft rough lattice, then for every $S_{r}(X), S_{r}(Y), S_{r}(Z) \in L$,

$$
S_{r}(X) \wedge\left(S_{r}(Y) \vee S_{r}(Z)\right)=\left(S_{r}(X) \wedge S_{r}(Y)\right) \vee\left(S_{r}(X) \wedge S_{r}(Z)\right)
$$

Now if $S_{r}(X) \succeq S_{r}(Y)$, then $S_{r}(X) \wedge S_{r}(Y)=S_{r}(Y)$. Therefore $S_{r}(X) \wedge\left(S_{r}(Y) \vee\right.$ $\left.S_{r}(Z)\right)=S_{r}(Y) \vee\left(S_{r}(X) \wedge S_{r}(Z)\right)$.

\section{Conclusion}

Soft rough set is generalization of rough set based on soft set. In this paper, we established an algebraic connection between soft rough set and algebraic structure named as lattice. As a result, lattice structure has been developed on soft rough set and defined this concept as soft rough lattice based on soft approximation space. After that we investigated the several properties and theorems on soft rough lattice. Finally we have justified our proposed soft rough lattice with supporting examples by Hasse diagram. 


\section{REFERENCES}

[1] D. Molodtsov, Soft set theory - first results, Comput. Math. Appl. 37 (1999), 19-31.

[2] D. Molodtsov, The Theory of Soft Sets (in Russian), URSS Publishers, Moscow, 2004.

[3] P. K. Maji, A. R. Roy and R. Biswas, An application of soft sets in a decision making problem, Comput. Math. Appl. 44 (2002), 1077-1088.

[4] X. B. Yang, T. Y. Lin, J. Y. Yang, Y. Li and D. J. Yu, Combination of interval-valued fuzzy set and soft set, Comput. Math. Appl. 58 (2009), 521-527.

[5] P. K. Maji, R. Biswas and A. R. Roy, Soft set theory, Comput. Math. Appl. 45 (2003), 55-562.

[6] H. Aktas and N. Cağman, Soft sets and soft groups, Inform. Sci. 177 (2007), 2726-2735.

[7] R. Nagarajan and G. Meenambigai, An application of soft set to lattice, Kragujevac J. Math. 35(1) (2011), 61-73.

[8] F. Li, Soft lattice, Bull. Pol. Acad. Sci. Math. 10(4) (2010), 56-58.

[9] Z. Pawlak, Rough sets, Int. J. Comput. Inf. Sci. 11(5) (1982), 341-356.

[10] T. B. Iwinski, Algebraic approach to rough sets, Bull. Pol. Acad. Sci. Math. 35(9-10) (1987), 673-683.

[11] D. Rana and S. K. Roy, Rough set approach on lattice, Journal of Uncertain Systems 5(1) (2011), 72-80.

[12] F. Feng, X. Liu, V. Leoreanu-Fotea and Y. B. Jun, Soft sets and soft rough sets, Inform. Sci. 181 (2011), 1125-1137.

[13] S. Bera and S. K. Roy, Rough modular lattice, Journal of Uncertain Systems 7(4) (2013), 289-293.

[14] S. Bera and S. K. Roy, Distributive lattice: a rough set approach, Malaya Journal of Matematik 2(3) (2014), 273-276.

[15] F. Karaaslan, N. Cagman and S. Enginoglu, Soft lattices, Journal of New Results in Science 1 (2012), 5-17.

[16] F. Karaaslan and N. Cagman, Fuzzy soft lattice theory, ARPN Journal of Science and Technology 3(3) (2013), 248-253.

${ }^{1}$ Department of Applied Mathematics with Oceanology and Computer ProgramMING,

VIDYASAGAR UNIVERSITY,

MidnAPORE-721102, WeST BEngal, India

E-mail address: sankroy2006@gmail.com

${ }^{2}$ Department of Applied Mathematics with Oceanology and Computer ProgramMING,

VIDYASAGAR UNIVERSITY,

Midnapore-721102, West Bengal, India

E-mail address: bera.bapi@gmail.com 